\title{
Influence of the morphologic evolution of the eutectic carbides at high temperature on the thermal expansion behavior of refractory cast alloys
}

\author{
Patrice Berthod, Cédric Heil, Lionel Aranda \\ Institut Jean Lamour (UMR 7198), department CP2S \\ Faculty of Sciences and Techniques, UHP Nancy 1, Nancy - University \\ BP 70239, 54506 Vandoeuvre-lès-Nancy - France
}

Corresponding author's e-mail: patrice.berthod@centraliens-lille.org

Corresponding author's phone: (33)3 83684666 and fax number: (33)3 83684611

\begin{abstract}
Two alloys particularly rich in carbides, a nickel-based one reinforced by chromium carbides and a cobalt-based one strengthened by tantalum carbides were characterized by metallography and their hardness and thermal expansion behavior tested, after alloys had undergone a more or less long aging treatment at high temperature. Aging induces a progressive coarsening and/or fragmentation of these interdendritic carbides, with as first consequence a decrease in hardness. Also due to these morphology changes, aging the alloys on long times leads to a loss of effect of the carbides on the thermal expansion behavior of the alloys. The total thermal expansion, initially lowered by the rigid carbides network, is then free again. Indeed, the high temperature phenomenon of plastic or viscous-plastic deformation in compression of the matrix by the initial continuous carbides network has almost disappeared.
\end{abstract}

Keywords: metals and alloys (A); microstructure (C); thermal expansion (C); mechanical properties (C); computer simulations (D)

\section{Introduction}

For a superalloy in service, remaining a long time exposed to very high temperatures generally induces significant microstructure changes, in presence or not of stresses applied to the pieces. Among the modifications which are usually observed in the microstructure of industrial superalloys, one can give as examples: the establishment of a rafting structure for intermetallic precipitates in $\gamma^{\prime}$-reinforced nickel-based superalloys [1], coarsening of grains and morphology evolution of carbides [2], the fragmentation of $\mathrm{TaC}$ carbide fibers in eutectic Cobased superalloys directionally solidified [3], or the same phenomenon but affecting the interdendritic TaC-carbides [4-6] or other MC-carbides [7] with which several equiaxed cast superalloys are strengthened. Since the interdendritic carbides play an important role at high temperature for both the mechanical resistance of the alloys (as reinforcing phases [1,2]) and the oxidation/corrosion resistance (grain boundaries = special diffusion paths notably for $\mathrm{Cr}$ [89]), it appears that such carbides modifications may influence the mechanical / thermomechanical behavior of these alloys, as well as their oxidation rate.

The aim of this work is to learn more about the possible effects of carbides modifications on the thermal expansion of conventionally-cast carbides-rich refractory alloys, between room temperature and $1200^{\circ} \mathrm{C}$. This was done by studying the case of a simple carbon-rich nickel 
alloy and a more complex Co-based alloy containing $\mathrm{TaC}$ carbides with high densities, after preliminarily aging treatments at $1200^{\circ} \mathrm{C}$ performed for different durations.

\section{Experimental details of the study}

\subsection{The studied alloys}

Three 100g-ingots of a nickel alloy (targeted composition: $\mathrm{Ni}($ bal.)-30\%Cr-1\%C in weight percent) and three 100g-ingots of a cobalt-based superalloy (targeted: $\mathrm{Co}(\mathrm{bal})-.10 \% \mathrm{Ni}-$ $30 \% \mathrm{Cr}-0.5 \% \mathrm{C}-7.5 \% \mathrm{Ta}$ in wt.\%) were cast in the water-cooled copper crucible of a High Frequency induction furnace (CELES). This was achieved under an inert atmosphere of several hundreds millibars of pure argon, by melting pure elements together (purity higher than 99\% in mass): $\mathrm{Co}, \mathrm{Ni}, \mathrm{Cr}$ and $\mathrm{Ta}$ supplied by Alfa Aesar, and $\mathrm{C}$ added as pure graphite. With either $1 \mathrm{wt} . \% \mathrm{C}$ and a high content in chromium, or $0.5 \mathrm{wt} . \% \mathrm{C}$ and $7.5 \mathrm{wt} . \% \mathrm{Ta}$, chromium carbides or tantalum carbides can be present with high densities in the microstructures, of the nickel alloy and of the cobalt alloy respectively. The two alloys are elsewhere able to resist high temperature oxidation for several tens or hundreds hours (depending on both the temperature and the nature of the corrosive environment), thanks to their $30 \mathrm{wt} . \%$ of chromium. The role of the 10wt.\% of nickel present in the cobalt alloy is the stabilization of the FCC structure of matrix, down to sufficiently low temperatures.

For each alloy, one of three ingots was heated at $20 \mathrm{~K} \mathrm{~min}^{-1}$ from room temperature to $1200^{\circ} \mathrm{C}$, maintained at this temperature during 5 hours, then air-cooled. A similar heat treatment was applied for the second and the third ingots of each alloy, but for longer durations of the isothermal dwell: 25 hours and 100 hours.

\subsection{Metallographic preparation and microstructure characterization}

The ingots were thereafter cut using a Buehler Isomet 5000 precision saw, in order to keep only the zone preserved from possible microstructure modifications possibly caused by high temperature oxidation. One sample per ingot was embedded in a cold resin (Escil CY230 + HY956) and the mounted samples were polished by using SiC paper from 120 to 1,200 grit under water, then with a $1 \mu \mathrm{m}$-diamond paste.

A Scanning Electron Microscope (SEM, model: XL30 Philips) was used for metallographic observations, essentially in the Back Scattered Electrons mode (BSE) under an acceleration voltage equal to $20 \mathrm{kV}$. The chemical composition of each alloy was analyzed in the bulk on several locations, by using a Cameca SX microprobe in a defocalized mode (magnification: $\times 400)$. A diffractometer (Bruker XPERT-Pro) was also used to complete the metallographic characterization, with X-ray diffraction results.

The proportions of carbides were determined by image analysis for the two alloys in their three aged states, by measuring their surface fractions on five BSE micrographs randomly taken in the bulk of each sample. The BSE detector led to different levels of gray, depending on the average atomic number of the phases, allowing a good separation of the matrix (gray), the chromium carbides (darker than matrix) and the tantalum carbides (whiter than matrix). The Photoshop CS software (Adobe ) allowed the measurement of these experimental surface fractions of carbides. The latter ones were supposed to be close to the volume fractions. 


\subsection{Thermal analysis}

In order to specify the temperature ranges of melting and of solidification Differential Thermal Analysis (DTA) experiments were performed using a Setaram TGA 92-16.18 apparatus, in order to measure the temperatures of fusion's start and of fusion's end of the alloys. The thermal cycle was composed of a heating rate of $20 \mathrm{~K} \mathrm{~min}^{-1}$ up to $1200{ }^{\circ} \mathrm{C}$, followed by a slower heating at $5 \mathrm{~K} \mathrm{~min}^{-1}$ up to $1500{ }^{\circ} \mathrm{C}$ for a better accuracy in this zone of temperatures. The cooling was done first at $5 \mathrm{~K} \mathrm{~min}^{-1}$ down to $1200^{\circ} \mathrm{C}$, then at $20 \mathrm{~K} \mathrm{~min}^{-1}$ down to room temperature. The solidus and liquidus temperatures of the alloys were supposed to be close to the temperatures of fusion's start and fusion's end determined in the heating part of the DTA curve.

\subsection{Thermodynamic calculations}

The theoretical stable microstructure states at $1200^{\circ} \mathrm{C}$ of the two alloys were determined by using the Thermo-Calc version $\mathrm{N}$ software and the SSOL database (SGTE) enriched with the descriptions of the following binary and ternary systems : Ta-C [10], Co-Ta [11], Ni-Ta [12], Cr-Ta [13], Co-Ta-C [14], Ni-Cr-Ta [15] (only four ternary systems were still missing in the new database: Co-Cr-Ta, Co-Ni-Ta, Ni-Ta-C and $\mathrm{Cr}-\mathrm{Ta}-\mathrm{C})$. Calculations were carried out to specify, when the aging duration increases, the degree of convergence of the alloys towards the theoretic stable state at $1200^{\circ} \mathrm{C}$, first by comparing the microstructures of the alloys (after each of the three heat treatments) to the metallurgical stable state at $1200^{\circ} \mathrm{C}$, and second to compare the temperatures of fusion's start and fusion's end to the theoretic solidus and liquidus temperatures. All calculations were performed by considering the real chemical composition of each ingot.

\subsection{Hardness measurements}

The hardness evolution of the two alloys with the $1200^{\circ} \mathrm{C}$-treatment duration was studied by Vickers macro-indentation performed using a Testwell Wolpert apparatus. Five indentations in the bulk of each metallographic sample with a load of $30 \mathrm{~kg}$ were performed. The average value and the standard deviation were calculated in each case.

\subsection{Dilatometry runs}

Thermal expansion was measured using a Setaram apparatus (model: TMA 92-16.18) on parallelepipeds cut in each ingot. The dimensions of these samples were about $4 \mathrm{~mm} \times 4 \mathrm{~mm}$ (square main faces) $\times 2 \mathrm{~mm}$ (direction of the characterized expansion). The heating was performed from room temperature up to $1200^{\circ} \mathrm{C}$ (rate: $10 \mathrm{~K} \times \mathrm{min}^{-1}$ ), followed by a dwell of 3600 seconds and finally a cooling down to room temperature (rate: $-10 \mathrm{~K} \times \mathrm{min}^{-1}$ ). Three evolutions of the sample's thickness were studied: the thermal expansion during the heating, the thermal contraction during the cooling, and the dimensional evolution during the 1 hourdwell at $1200^{\circ} \mathrm{C}$. 


\section{Results}

\subsection{Microstructure states of the alloys after the aging treatments}

The chemical compositions of the obtained alloys, characterized by Energy Dispersion Spectrometry using the EDS apparatus with which the SEM is equipped, are displayed in Table 1. They are close to the targeted contents and one can also consider that the three ingots of the same alloy (Ni-based or Co-based) have effectively the same compositions.

The microstructures of the two alloys after the three aging treatments are illustrated by the SEM micrographs given in Fig. 1. After the 5h-treatment, the microstructures of the two alloys are still totally analogous to their as-cast microstructures. The Ni-based alloy contains a dendritic matrix of FCC nickel containing a part of chromium and of carbon in solid solution, and an interdendritic network of primary chromium carbides forming a eutectic compound with matrix. Secondary carbides can also be observed in the matrix. After more time spent at $1200^{\circ} \mathrm{C}$, there is a progressive morphology change of the primary carbides which are coarsened / rounder than before, while the secondary carbides have disappeared. This is particularly true between the as-cast/5h-aged state and the $100 \mathrm{~h}$-aged state. In contrast, no difference was observed concerning the carbides natures: they are still $\mathrm{Cr}_{7} \mathrm{C}_{3}$, even after 100 hours of aging at $1200^{\circ} \mathrm{C}$ (Fig. 2).

The Co-based alloy, the microstructure of which is already slightly different after 5 hours spent at $1200^{\circ} \mathrm{C}$ by comparison to its as-cast state, goes on evolving for longer times at $1200^{\circ} \mathrm{C}$ since the primary tantalum carbides become more and more divided into alignments of small and round $\mathrm{TaC}$ carbides. Here too, their nature does not change (Fig. 3). However, spectra of $\mathrm{X}$-ray diffraction tend qualitatively showing that the FCC part of matrix still remaining after cooling to room temperature tends to be more present after $100 \mathrm{~h}$-aging than after only $5 \mathrm{~h}$ aging.

\subsection{Carbide fractions and hardness of the alloys}

In order to get more quantitative data about the populations of carbides in the two alloys after the three different aging durations, measurements of the surface fractions of chromium carbides were performed for the Ni-based alloy and of tantalum carbides for the Co-based alloy. The results led to the curves of evolution presented in the two graphs displayed in Fig. 4. The volume fraction of $\mathrm{Cr}_{7} \mathrm{C}_{3}$ carbides stays almost constant, independently on the aging duration (even if there is maybe a little tendency to increase), while the volume fraction of $\mathrm{TaC}$ carbides obviously decreased during the first tens hours before staying almost constant. Thermodynamic calculations were also performed using Thermo-Calc for the chemical composition of each ingot and the aging temperature. This led to verify that effectively carbides are $\mathrm{Cr}_{7} \mathrm{C}_{3}$ and $\mathrm{TaC}$ at $1200^{\circ} \mathrm{C}$ and showed that matrixes were, at this same temperature, $\mathrm{FCC}$ in the two cases. The parts of HCP in the matrix of the cobalt-based ingots appeared during the cooling. Volume fractions were obtained from the mass fractions calculated by Thermo-Calc by using the following densities: 8.1 for Ni-based matrix, 8.9 for Co-based matrix, 6.94 for $\mathrm{Cr}_{7} \mathrm{C}_{3}$ carbide and 14.5 for $\mathrm{TaC}$ carbides (all in $\mathrm{g} \mathrm{cm}^{-3}$ ) [16]. There is little difference (taking into account the standard deviation values) between the final volume fraction and the value determined with Thermo-Calc calculations. The $\mathrm{TaC}$ volume fraction significantly converged to the equilibrium value, while this was obviously done for the $\mathrm{Cr}_{7} \mathrm{C}_{3}$ volume fraction before 5 hours of heat treatment. 
Hardness measurements, achieved under $30 \mathrm{~kg}$, logically led to values for the three aging states of the Co-based alloy which are higher than for the three aging states of the Ni-based alloy (Fig. 5). In the two cases the Vickers hardness decreases rapidly between the 5h-aged state and the $25 \mathrm{~h}$-aged state. This decrease goes on thereafter, but slower, for the cobalt alloy. In contrast hardness seems stabilized after 25h-aging for the Ni-based alloy.

\subsection{Intervals of fusion and of solidification}

Differential Thermal Analysis runs were performed for the two alloys in their three aged states. The DTA curves for the two extreme aged states are displayed in Fig. 6. One can first see that the endothermic peaks (fusion part) are better distinguished after only $5 \mathrm{~h}$-aging than after $100 \mathrm{~h}$-aging, while the exothermic peaks (solidification part) are logically not dependent on the aging duration. No significant difference can be noted between the measured temperatures of fusion's start and of fusion's end for the two extreme aging states, and the calculated solidus temperatures are in good agreement with the temperatures of fusion's start (Table 2). In contrast this is less true for the liquidus temperatures).

\subsection{Thermal expansion behaviors}

When the samples are heated from room temperature up to $1200^{\circ} \mathrm{C}$, their thickness increases more or less regularly, while it decreases thereafter during the cooling. The deformation curves are presented in Fig. 7 for the two extreme aged states of the Ni-based alloy and in Fig. 8 for the Co-based alloy. It appears first that the maximal dilatation is almost the same for the Ni-based alloy and for the Co-based alloy for the same duration of preliminary aging. In contrast, for a same alloy, the expansion when arriving to $1200^{\circ} \mathrm{C}$ for the $5 \mathrm{~h}$-aged state $(1.59 \%$ and $1.69 \%$ for the Ni-based alloy and for the Co-based alloy respectively) is significantly lower than for the $100 \mathrm{~h}$-aged states (1.93\% and $1.89 \%$ respectively). This can be found again for the average thermal expansion coefficients: indeed $\alpha_{100-1200^{\circ} \mathrm{C}}$ for the $5 \mathrm{~h}$-aged state (15.8 and $16.7 \times 10^{-6} \mathrm{~K}^{-1}$ for the Ni-based alloy and for the Co-based alloy respectively) is significantly lower than for the $100 \mathrm{~h}$-aged state $\left(18.4\right.$ and $18.3 \times 10^{-6} \mathrm{~K}^{-1}$ respectively). Another difference between the two aged states is what is occurred during the 1 hour-isothermal dwell: for the $5 \mathrm{~h}$-aged alloys there is a contraction at $1200^{\circ} \mathrm{C}$, significant for the Ni-based alloy ($0.04 \%)$ and particularly important for the Co-based alloy $(-0.21 \%)$. When alloys were preliminarily aged during 100 hours, the isothermal contraction at $1200^{\circ} \mathrm{C}$ exists too but is much less important for the Co-based alloy and almost inexistent for the Ni-based alloy. This isothermal contraction, which apparently followed a start of contraction already occurring before the end of heating (especially in the case of the 5h-aged Co-based alloy), is responsible of a significant part of the permanent negative deformation after return to $100^{\circ} \mathrm{C}(-0.16 \%$ and $0.27 \%$ for the Ni-based alloy and for the Co-based alloy respectively). Near the end of heating and during the beginning of cooling, the alloys were also subjected to a contraction phenomenon which participates thereafter to the total contraction after return to $100^{\circ} \mathrm{C}$. The values deduced from these curves are listed in Table 3.

In order to better examine how the contraction acts during the isothermal stage it can be useful to plot the dilatometry results in the $\{$ deformation $=\mathrm{f}$ (time) $\}$ scheme. The corresponding curves for the Ni-based alloy after $5 \mathrm{~h}$-aging and $100 \mathrm{~h}$-aging are displayed in Fig. 9 and the curves for the Co-based alloy in Fig. 10. In each case an enlargement of the dwell 
part is added. One can see now that in the three cases of significant contraction during the hour spent at $1200^{\circ} \mathrm{C},(5 \mathrm{~h}$-aged Ni-based, 5h-aged and $100 \mathrm{~h}$-aged Co-based alloys), the isothermal contraction is initially fast then it progressively decelerates.

\section{Discussion}

During solidification the mechanisms of development of the microstructures do not always allow the alloys to strictly respect the natures, the volume fractions, and also the morphologies of phases with which these alloys could be in metallurgical equilibrium at all the successive temperatures. This is true for the primary carbides the growth mechanisms of which lead to elongated shapes. At room temperature these shapes remain as formed at solidification and they can influence the properties of the alloys. If the latter are heated again up to high temperature, their properties depend in a first time on the still elongated shape of the interdendritic carbides, but they may thereafter progressively change with the morphology evolution of the carbides due to the reduction of interfacial energy. Hence, the high temperature mechanical properties can be logically changed with the coarsening of chromium carbides or with the fractioning of tantalum carbides, since these carbides are important interdendritic reinforcing particles. These morphology changes induce a weakening of the alloy but also improvements of ductility and toughness).

Changes in Young's modulus or ultimate tensile strength are not the sole possible properties modifications resulting from carbides fragmentation [17]. It was for example seen recently for the same alloys [18] that such modifications of the primary carbides, which are present in the grain boundaries along which species involved in the oxidation phenomena (e.g. $\mathrm{Cr}$ ) diffuse with easiness, can lead to changes in the kinetic of oxidation at high temperature: the longer the aging duration, the faster the mass gain by oxidation (especially at $1200^{\circ} \mathrm{C}$ ).

In this study, one saw in a first time that the aging at high temperature led to a lower fraction of TaC carbides (as well as a slightly higher proportion of FCC phase in matrix) after cooling in the Co-based alloy, while no such changes were seen for the chromium carbides of the Ni-based alloy. The chemical homogenization which resulted from the first hours of aging for the Co-based matrix smoothed the segregations developed during solidification, and the locally too high fractions of $\mathrm{TaC}$ were then corrected, and they better fitted the thermodynamic calculations results. This led for this alloy to a decrease in hardness which went on thereafter because of $\mathrm{TaC}$ fragmentation (already seen for other $\mathrm{TaC}$-strengthened cobalt based superalloys [17]), although the carbide fraction had become already constant. Another possible effect of the decrease in $\mathrm{TaC}$ fractions in the Co-based alloy during the first hours of aging is a slight but global homogeneous enrichment of the matrix in both carbon and tantalum atoms. This possibly led to a better stabilization of austenite at low temperature, which may result in a higher proportion of FCC against HCP for the matrix at the end of cooling, as qualitatively shown by X-ray diffraction. The coarsening of the chromium carbides in the Ni-based alloy, which also favors a loss of continuity for the interdendritic carbides network at constant volume fraction, also induces a decrease in hardness, but much slower than the one due to TaCfragmentation. In contrast, the interval of fusion was not really changed by the microstructure consequences of aging.

Concerning the thermal expansion of the alloys versus the different aging durations, one can first remark that the presence of a significant volume fraction of carbides led to thermal expansions which are slower than usually for nickel or cobalt-based alloys without such quantities of carbides $\left(\alpha \cong 20 \times 10^{-6} \mathrm{~K}^{-1}\right)$. Indeed, in the $5 \mathrm{~h}$-aged state (which is close to the as- 
cast state), the whole curves have a lower average slope, which is quantitatively found again by considering the average coefficients of thermal expansion $\left(\alpha \cong 16\right.$ or $\left.17 \times 10^{-6} \mathrm{~K}^{-1}\right)$. This is clearly due to both the high carbides fractions and the low thermal expansion coefficients of $\mathrm{Cr}_{7} \mathrm{C}_{3}\left(\alpha \cong 11 \times 10^{-6} \mathrm{~K}^{-1}\right)$ or $\mathrm{TaC}\left(\alpha \cong 6.3 \times 10^{-6} \mathrm{~K}^{-1}\right)$ carbides [19]. The decrease in dilatation which was observed at the end of heating for the two 5h-aged alloys, as well as the progressive contraction during the isothermal dwell, were already observed but for alloys not so rich in carbon and in carbides [20]. In addition, in these previous results the dwell duration was only 10 minutes, while it is here 1 hour which allows to observe the contraction progression on longer times and its deceleration. This permits here confirming the mechanisms previously explained [20], which can be illustrated by Fig. 11.

All along the heating the matrix tends to undergo a thermal expansion greater than the carbides one. Therefore, since the two phases are mixed together with interpenetration of their networks, the mechanical equilibrium necessarily imposes that matrix is subjected to a more and more intensive compression and the carbide network is in a state of more and more intensive traction. When temperature has become high enough to weaken the metallic matrix, this one begins to be plastically deformed in compression by the carbide network which remained very rigid. This leads to a deceleration of the elongation, and even to its inversion. When temperature arrived at the isothermal dwell, there is now no tendency of thermal expansion and the carbides network continues to viscoplastically compress the matrix, until an equilibrium between the decreased compressive action of the carbides network and the increasing resistance of the plastically deformed matrix is reached.

When a sufficient aging is applied, with as consequence a fragmented state for carbides and then a sufficient loss of continuity for their network, this effect can obviously disappear: 100 hours spent at $1200^{\circ} \mathrm{C}$ are sufficient to suppress the increasing compressive action of carbides on matrix: global thermal expansion coefficients of the whole alloys are higher, no deceleration of elongation occurs at high temperature and no isothermal contraction acts during the dwell.

\section{Conclusion}

The difference of thermal expansion behavior between the metallic matrix and the network of intergranular carbides can induce significant modifications for the thermal elongation of a piece made of the considered alloy. This can be a decrease in average thermal expansion coefficient (which is usually considered as beneficial) but also, if temperature becomes too high, a deformation of the matrix which is responsible of a not so interesting permanent deformation after return to room temperature, with as result a bad geometrical stability. Previous studies [21] showed that new increases in carbide volume fractions enhance the problem, but fortunately it appeared here that a sufficiently long aging can then reduce, and even suppress, the phenomenon by eliminating the carbides network continuity.

\section{Acknowledgements}

The authors thank the Common Service of Microanalysis of the Faculty of Science and Technologies of the University Henri Poincaré Nancy 1 (Electron microscopy) and Pascal Villeger (XRD analyses). 


\section{References}

[1] C. T. Sims, W. C. Hagel, The Superalloys, John Wiley \& Sons, New York, 1972.

[2] E. F. Bradley, Superalloys: a technical guide, ASM International, Metals Park, 1988.

[3] J.F. Stohr, Annales de Chimie 5 (1980) 226-241.

[4] P. Berthod, S. Michon, L. Aranda, S. Mathieu, J.C. Gachon, Calphad 27 (2003) 353359.

[5] P. Berthod, L. Aranda, C. Vébert, S. Michon, Calphad 28 (2004) 159-166.

[6] P. Berthod, Y. Hamini ; L. Aranda, L. Héricher, Calphad 31 (2007) 351-360.

[7] P. Berthod, Journal of Alloys and Compounds 481 (2009) 746-754.

[8] P. Kofstad, High Temperature Corrosion, Elsevier Applied Science, London, 1988.

[9] D. Young, High Temperature Oxidation and Corrosion of Metals, Elsevier Corrosion Series, Oxford, 2008.

[10] K. Frisk, A. Fernandez Guillermet, Journal of Alloys and Compounds 238 (1996) 167-179.

[11] Z.-K. Liu, Y. Austin Chang, Calphad 23 (1999) 339-356.

[12] I. Ansara, M. Selleby, Calphad 18 (1994) 99-107.

[13] N. Dupin, I. Ansara, Journal of Phase Equilibria 14 (1993) 451-456.

[14] L. Dumitrescu, M. Ekroth, B. Jansson, Metallurgical and Materials Transactions 32A (2001) 2167-2174.

[15] N. Dupin, I. Ansara, Z. Metallkd. 87 (1996) 555-561.

[16] Handbook of Chemistry and Physics, 57 ${ }^{\text {th }}$ ed., 1977.

[17] S. Michon, L. Aranda, P. Berthod, P. Steinmetz, Revue de Métallurgie C.I.T./Science et Génie des Matériaux, 9 (2004) 651-662.

[18] P. Berthod, L. Aranda, C. Heil, The Open Corrosion Journal 2 (2009) 150-156.

[19] G.V. Samsonov, Plenum Press Handbooks of High-Temperature Materials $N^{\circ} 2$. Properties Index, Plenum Press, New York, 1964.

[20] P. Berthod, Int. J. Mat. Res. (formerly Z. Metallkd.) 99(3) (2008) 265-272.

[21] P. Lemoine, P. Berthod, Ann. Chim. Sci. Mat. 34(2) (2009) 61-76. 
Table 1

Chemical compositions of the studied alloys (SEM/EDS, $\pm 1 \mathrm{wt} . \%$ )

\begin{tabular}{|c|c|c|c|c|c|c|}
\hline $\begin{array}{c}\text { Average } \\
\pm \text { Std deviation }\end{array}$ & ingot & aged & Co & Ni & Cr & Ta \\
\hline \multirow{2}{*}{ Ni alloy } & $\mathrm{N}^{\circ} 1$ & $5 \mathrm{~h}$ at $1200^{\circ} \mathrm{C}$ & $/$ & Bal. & 31.4 & $/$ \\
\cline { 2 - 7 }$(1.0$ wt.\%C) & $\mathrm{N}^{\circ} 2$ & $25 \mathrm{~h}$ at $1200^{\circ} \mathrm{C}$ & $/$ & Bal. & 29.0 & $/$ \\
\cline { 2 - 7 } & $\mathrm{N}^{\circ} 3$ & $100 \mathrm{~h}$ at $1200^{\circ} \mathrm{C}$ & $/$ & Bal. & 32.7 & $/$ \\
\hline \multirow{2}{*}{ Co alloy } & $\mathrm{N}^{\circ} 1$ & $5 \mathrm{~h}$ at $1200^{\circ} \mathrm{C}$ & Bal. & 9.7 & 31.3 & 7.5 \\
\cline { 2 - 8 }$(0.5$ wt.\%C $)$ & $\mathrm{N}^{\circ} 2$ & $25 \mathrm{~h}$ at $1200^{\circ} \mathrm{C}$ & Bal. & 10.0 & 31.3 & 7.7 \\
\cline { 2 - 8 } & $\mathrm{N}^{\circ} 3$ & $100 \mathrm{~h}$ at $1200^{\circ} \mathrm{C}$ & Bal. & 10.2 & 31.1 & 7.6 \\
\hline
\end{tabular}

Table 2

Values of the solidus temperatures and liquidus temperatures determined on the heating part of the DTA curves

\begin{tabular}{|c|c|c|c|c|c|}
\hline \multicolumn{2}{|c|}{ Temperatures } & \multicolumn{2}{|c|}{$\begin{array}{c}\text { Temperature of fusion start } \\
\text { / Solidus temperature } \\
\left({ }^{\circ} \mathrm{C}\right)\end{array}$} & \multicolumn{2}{|c|}{$\begin{array}{r}\text { Temperature of fusion end } \\
\text { / Liquidus temperature } \\
\left({ }^{\circ} \mathrm{C}\right)\end{array}$} \\
\cline { 3 - 7 } & & DTA & $\begin{array}{c}\text { Thermo } \\
- \\
\text { Calc }\end{array}$ & DTA & $\begin{array}{c}\text { Thermo } \\
- \\
\text { Calc }\end{array}$ \\
\hline \multirow{2}{*}{ Alloys } & $5 \mathrm{~h}$ & 1320 & 1316 & 1373 & 1341 \\
\cline { 3 - 7 } & $100 \mathrm{~h}$ & 1320 & 1317 & 1378 & 1338 \\
\hline \multirow{2}{*}{ Nickel alloy } & $5 \mathrm{~h}$ & 1273 & 1272 & 1402 & 1343 \\
\cline { 3 - 7 } & $100 \mathrm{~h}$ & 1265 & 1272 & 1395 & 1342 \\
\hline
\end{tabular}


Table 3

Values of the solidus temperatures and liquidus temperatures determined on the heating part of the DTA curves

\begin{tabular}{|c|c|c|c|c|c|}
\hline \multirow{2}{*}{\multicolumn{2}{|c|}{ Temperatures }} & \multicolumn{2}{|c|}{$\begin{array}{l}\text { Average thermal expansion } \\
\text { coefficients } \alpha{ }_{100^{\circ} \mathrm{C}-1200^{\circ} \mathrm{C}} \\
\left(\times 10^{-6} \mathrm{~K}^{-1}\right)\end{array}$} & \multicolumn{2}{|c|}{$\Delta \mathrm{l} / \mathrm{l}_{0}(\%)$ at $1200^{\circ} \mathrm{C}$} \\
\hline & & $\begin{array}{l}\alpha_{100^{\circ} \mathrm{C}-1200^{\circ} \mathrm{C}} \\
\text { heating }\end{array}$ & $\begin{array}{l}\alpha_{1200^{\circ} \mathrm{C}-100^{\circ} \mathrm{C}} \\
\text { cooling }\end{array}$ & $\begin{array}{l}\text { end of } \\
\text { heating }\end{array}$ & $\begin{array}{l}\text { start of } \\
\text { cooling }\end{array}$ \\
\hline \multicolumn{2}{|c|}{ Alloys } & \multicolumn{2}{|c|}{$\begin{array}{l}\text { final deformation after } \\
\text { return to } 100^{\circ} \mathrm{C}\end{array}$} & \multicolumn{2}{|c|}{ isothermal contraction } \\
\hline \multirow{4}{*}{ Nickel alloy } & \multirow{2}{*}{$5 \mathrm{~h}$} & 15.8 & 14.6 & $1.594 \%$ & $1.551 \%$ \\
\hline & & \multicolumn{2}{|c|}{$-0.163 \%$} & \multicolumn{2}{|c|}{$-0.043 \%$} \\
\hline & \multirow{2}{*}{$100 \mathrm{~h}$} & 18.4 & 17.2 & $1.931 \%$ & $1.965 \%$ \\
\hline & & \multicolumn{2}{|c|}{$+0.095 \%$} & \multicolumn{2}{|c|}{$+0.034 \%$} \\
\hline \multirow{4}{*}{ Cobalt alloy } & \multirow{2}{*}{$5 \mathrm{~h}$} & 16.7 & 15.7 & $1.692 \%$ & $1.484 \%$ \\
\hline & & \multicolumn{2}{|c|}{$-0.270 \%$} & \multicolumn{2}{|c|}{$-0.208 \%$} \\
\hline & \multirow{2}{*}{$100 \mathrm{~h}$} & 18.3 & 15.6 & $1.887 \%$ & $1.853 \%$ \\
\hline & & \multicolumn{2}{|c|}{$+0.101 \%$} & \multicolumn{2}{|c|}{$-0.034 \%$} \\
\hline
\end{tabular}




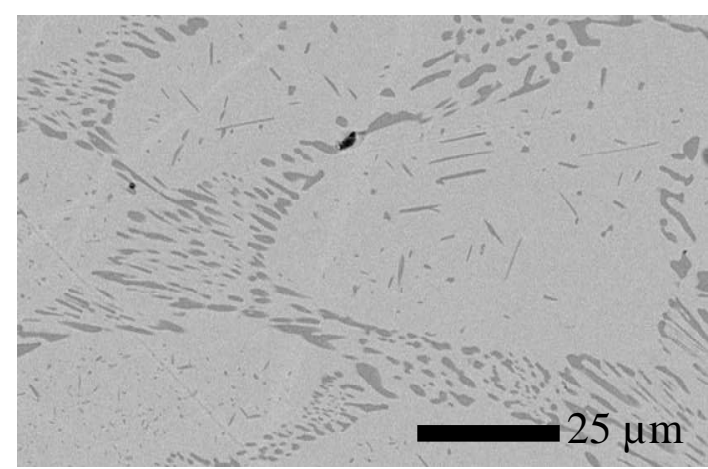

$\mathrm{Ni}$ alloy aged $5 \mathrm{~h}$ at $1200^{\circ} \mathrm{C}$

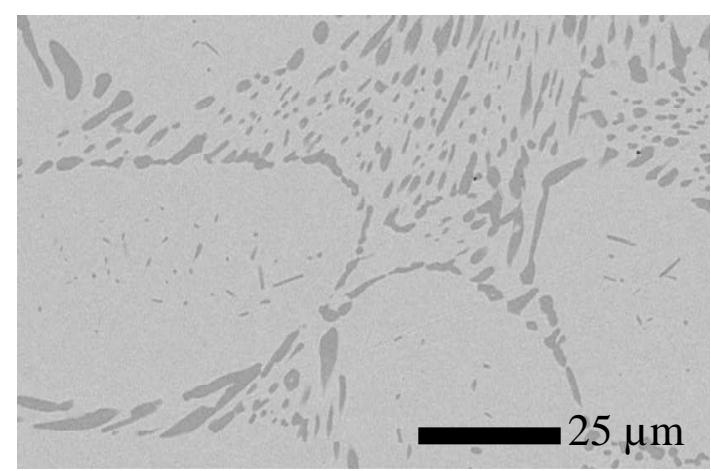

$\mathrm{Ni}$ alloy aged $25 \mathrm{~h}$ at $1200^{\circ} \mathrm{C}$

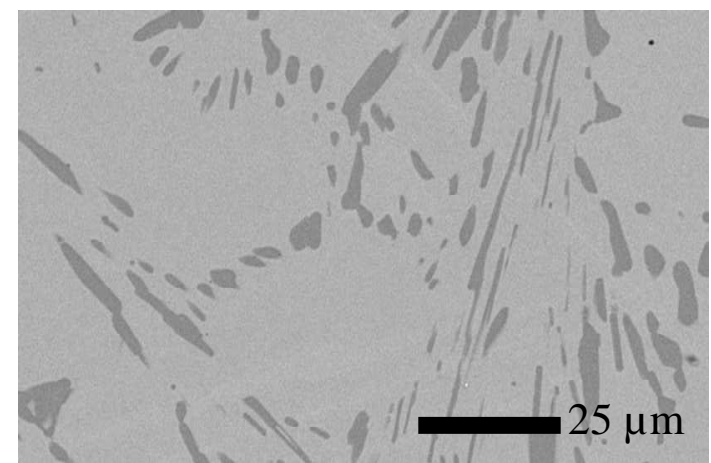

$\mathrm{Ni}$ alloy aged $100 \mathrm{~h}$ at $1200^{\circ} \mathrm{C}$

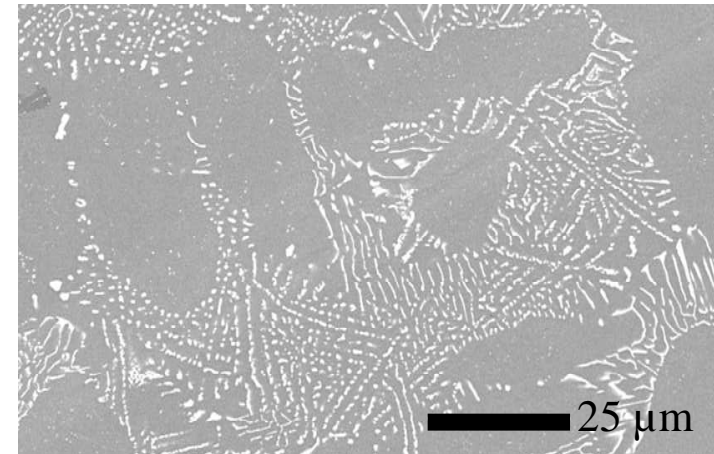

Co alloy aged $5 \mathrm{~h}$ at $1200^{\circ} \mathrm{C}$

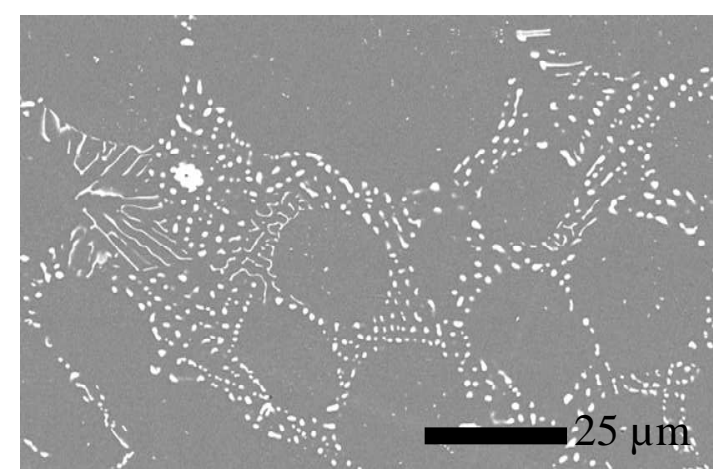

Co alloy aged $25 \mathrm{~h}$ at $1200^{\circ} \mathrm{C}$

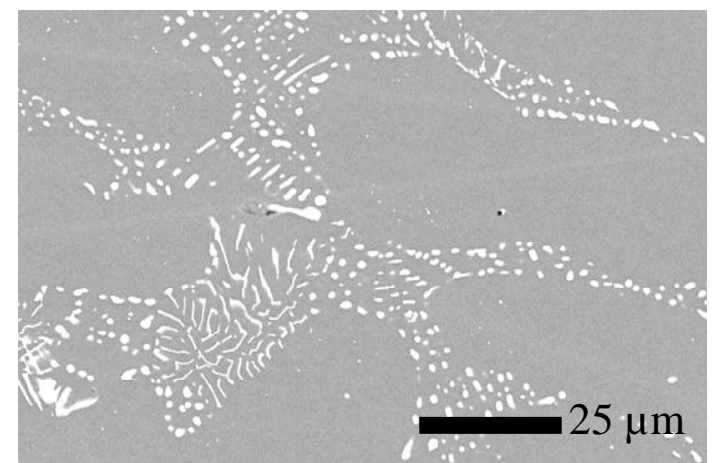

Co alloy aged $100 \mathrm{~h}$ at $1200^{\circ} \mathrm{C}$

Fig. 1.

Microstructures of the two alloys after each heat-treatment (SEM/BSE micrographs) 

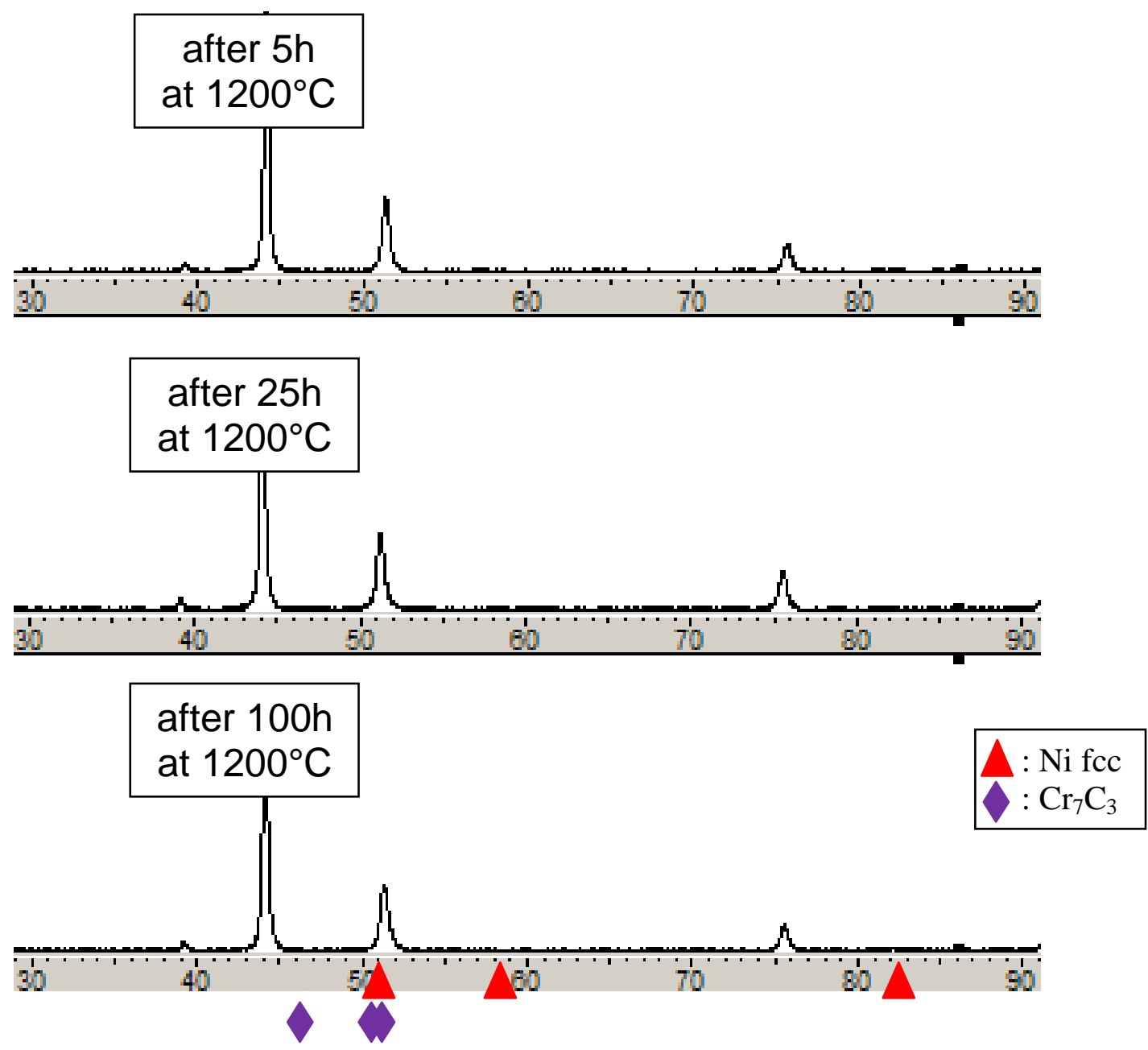

Fig. 2.

Diffraction patterns of the nickel alloys after the three heat-treatment durations 

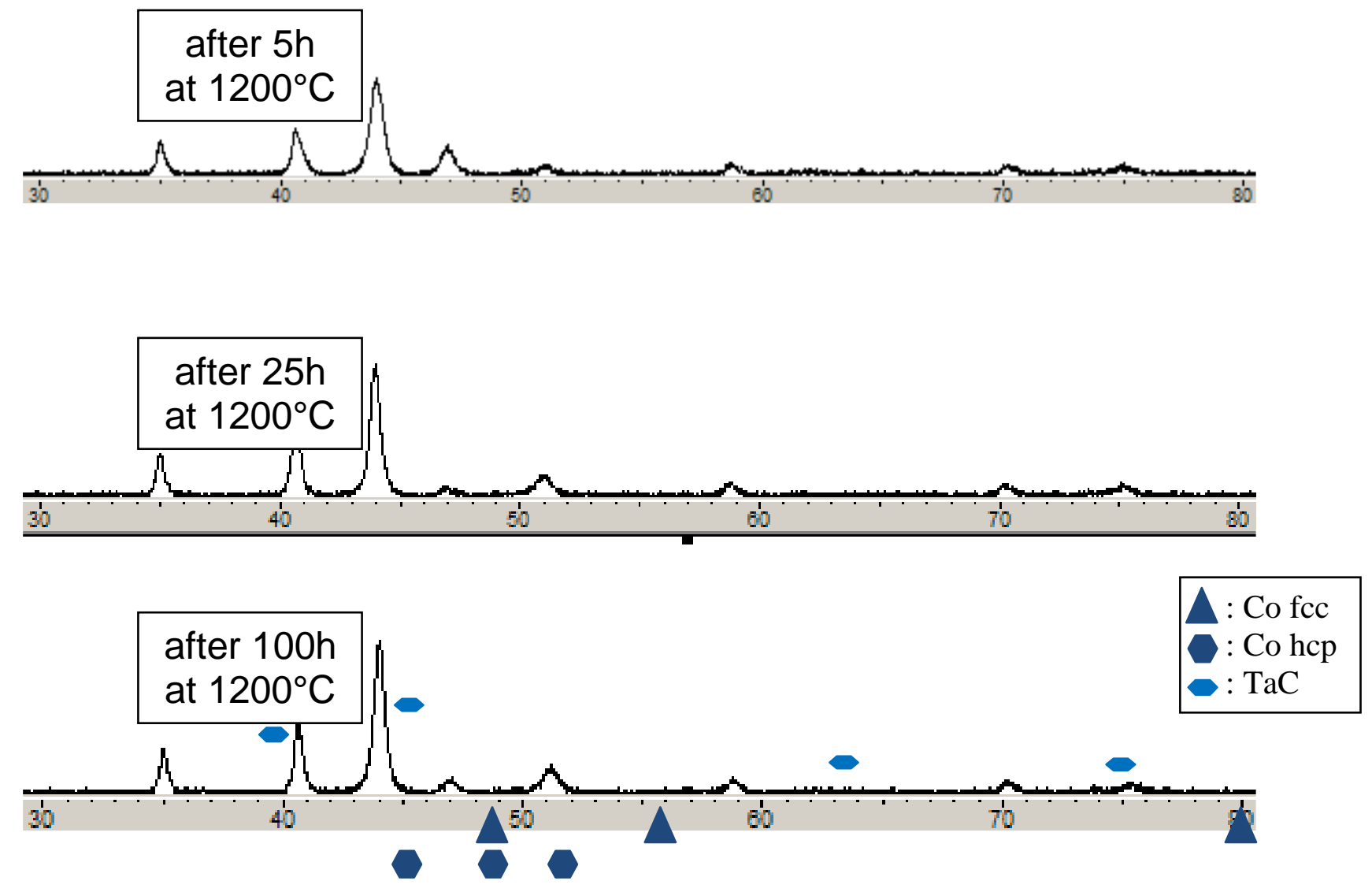

Fig. 3.

Diffraction patterns of the cobalt alloys after the three heat-treatment durations 

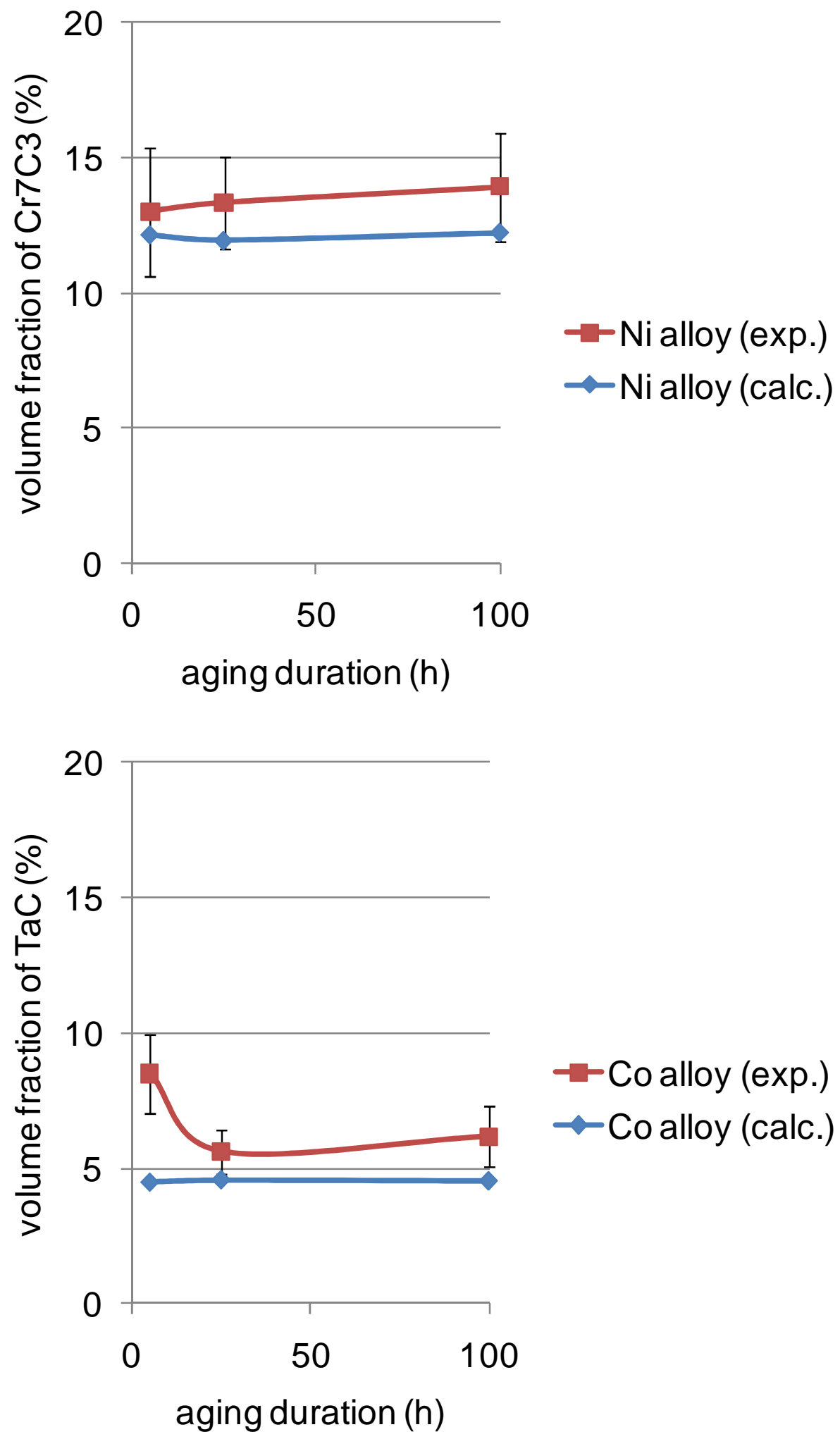

Fig. 4.

Evolution of the carbides volume fractions with the aging duration, with comparison with the ones calculated using Thermo-Calc from the real chemical composition of the three ingots used for the three heat-treatments (the $5 \mathrm{~h}$-aged cobalt alloy also contains $0.09 \%$ vol of $\mathrm{M}_{23} \mathrm{C}_{6}$ ) 


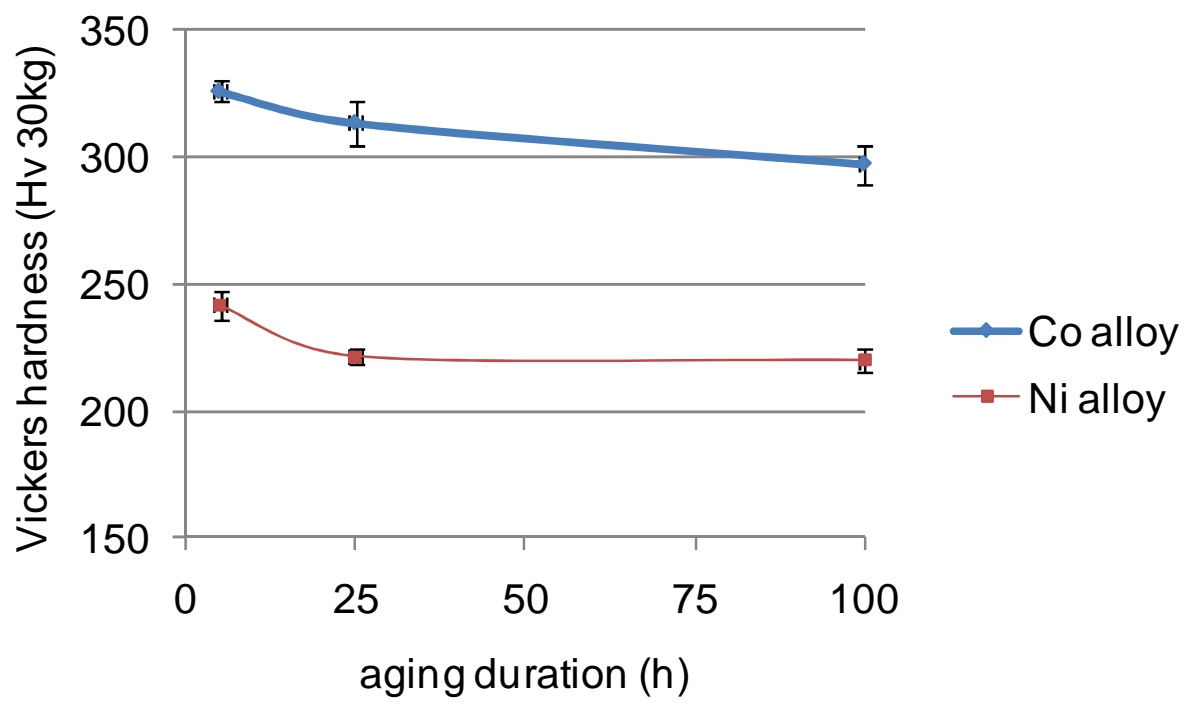

Fig. 5.

Evolution of the room-temperature hardness with the heat-treatment duration (Vickers hardness under a 30kg-load)
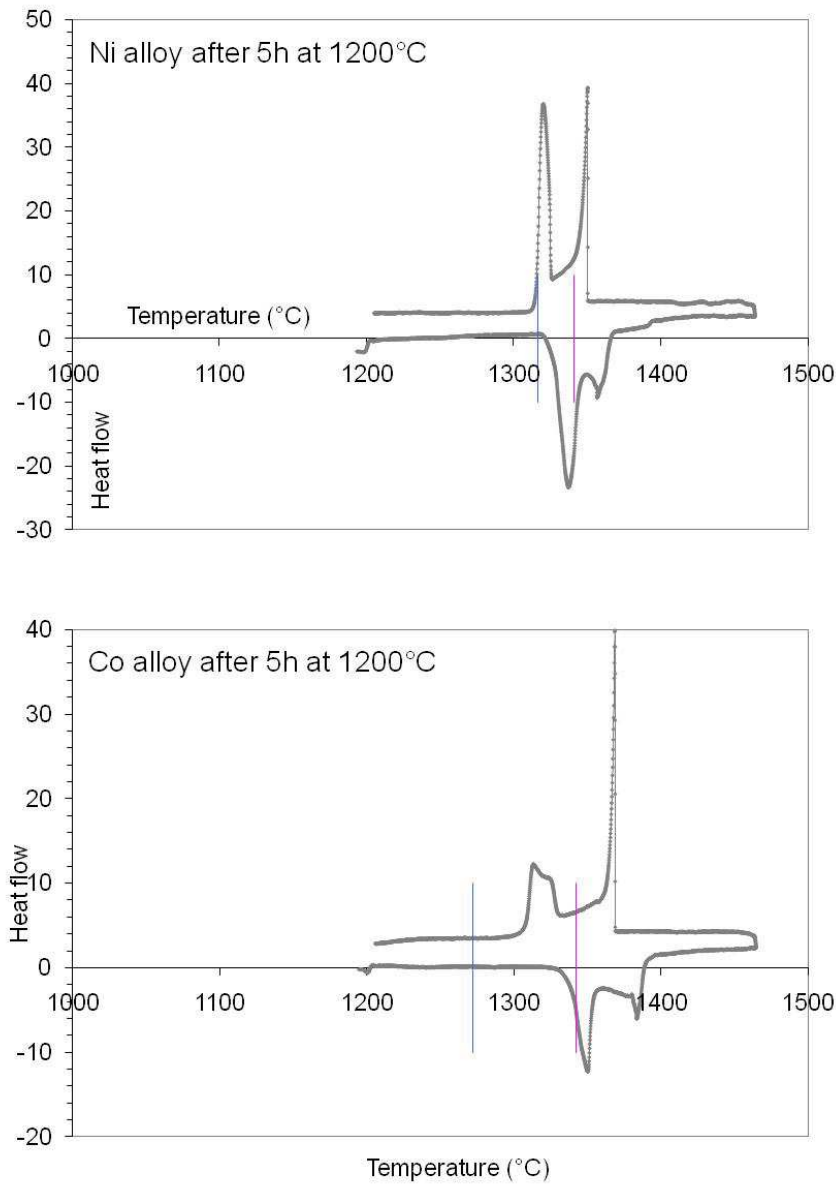

Fig. 6a.

Evolution of the DTA curves with the aging duration (here 5h) 

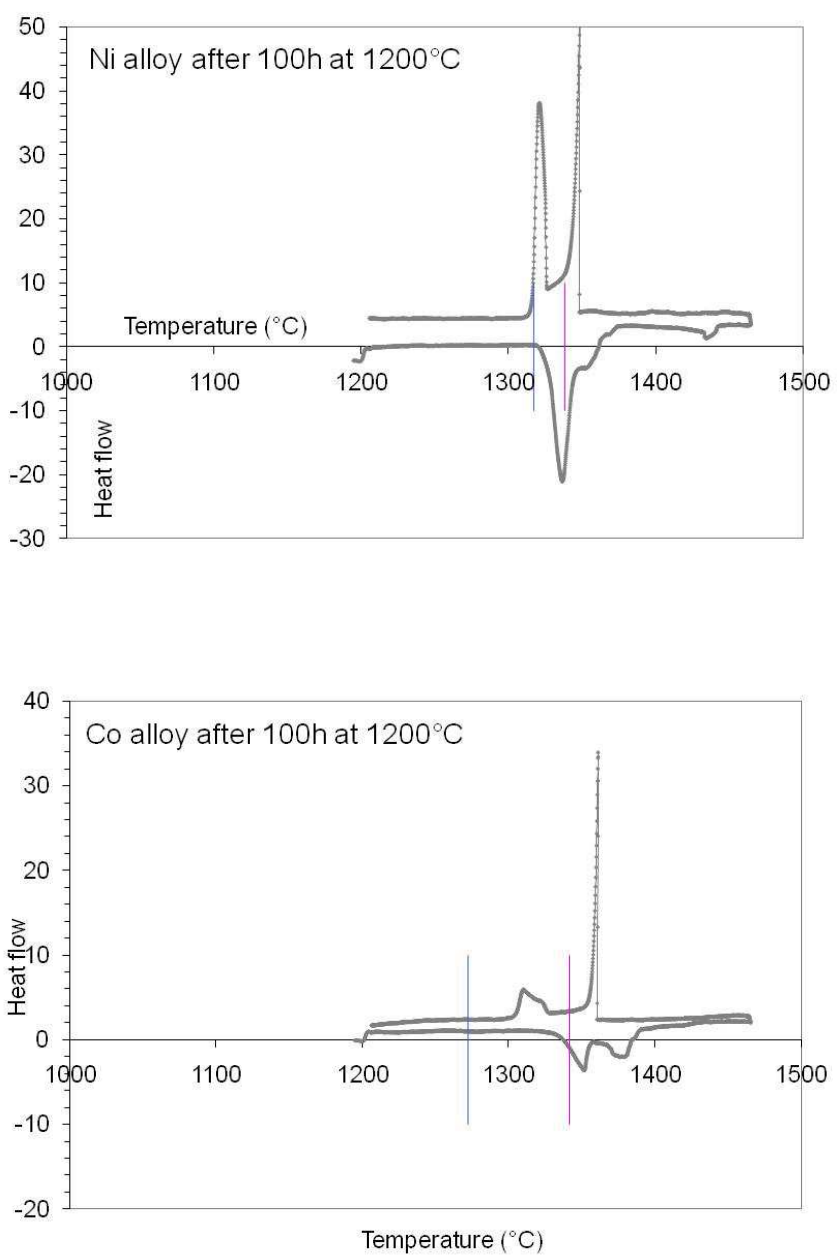

Fig. 6b.

Evolution of the DTA curves with the aging duration (here 100h) 

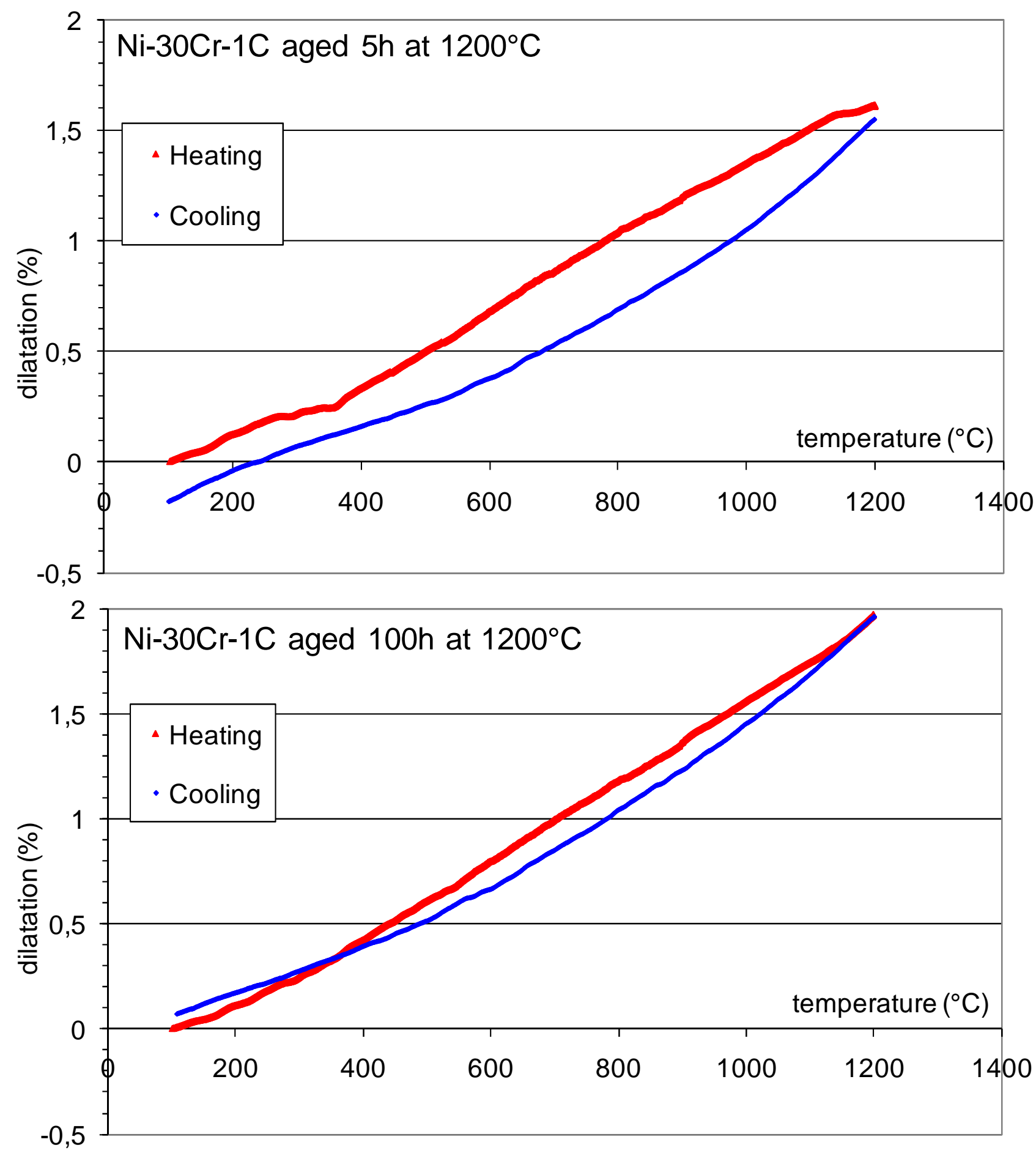

Fig. 7.

Dilatometry curves resulting from the thermal expansion experiments performed on the 5 h-aged Ni-based alloy and on the $100 \mathrm{~h} \mathrm{Ni-based} \mathrm{alloy}$ 


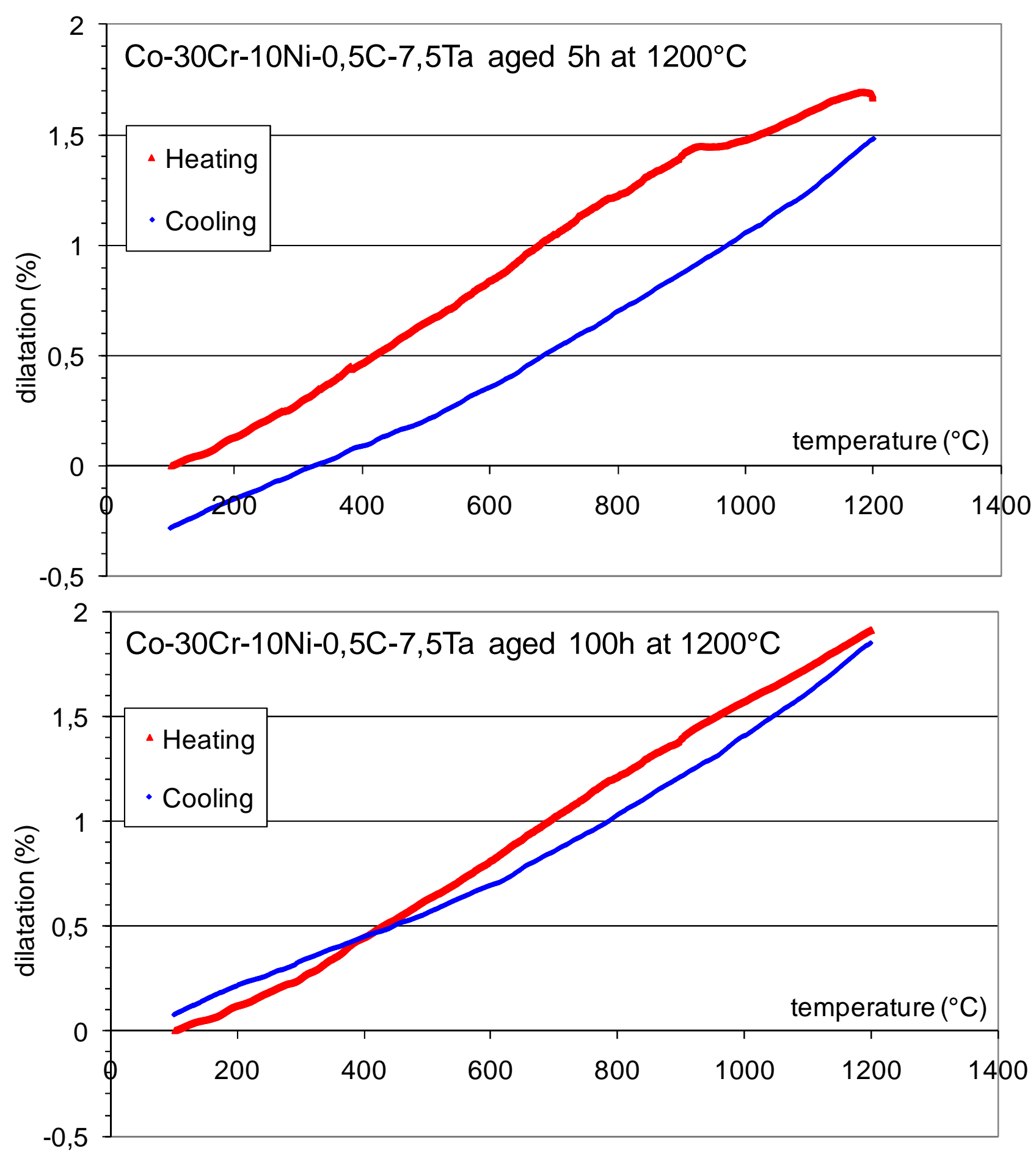

Fig. 8 .

Dilatometry curves resulting from the thermal expansion experiments performed on the 5h-aged Co-based alloy and on the 100h Co-based alloy 

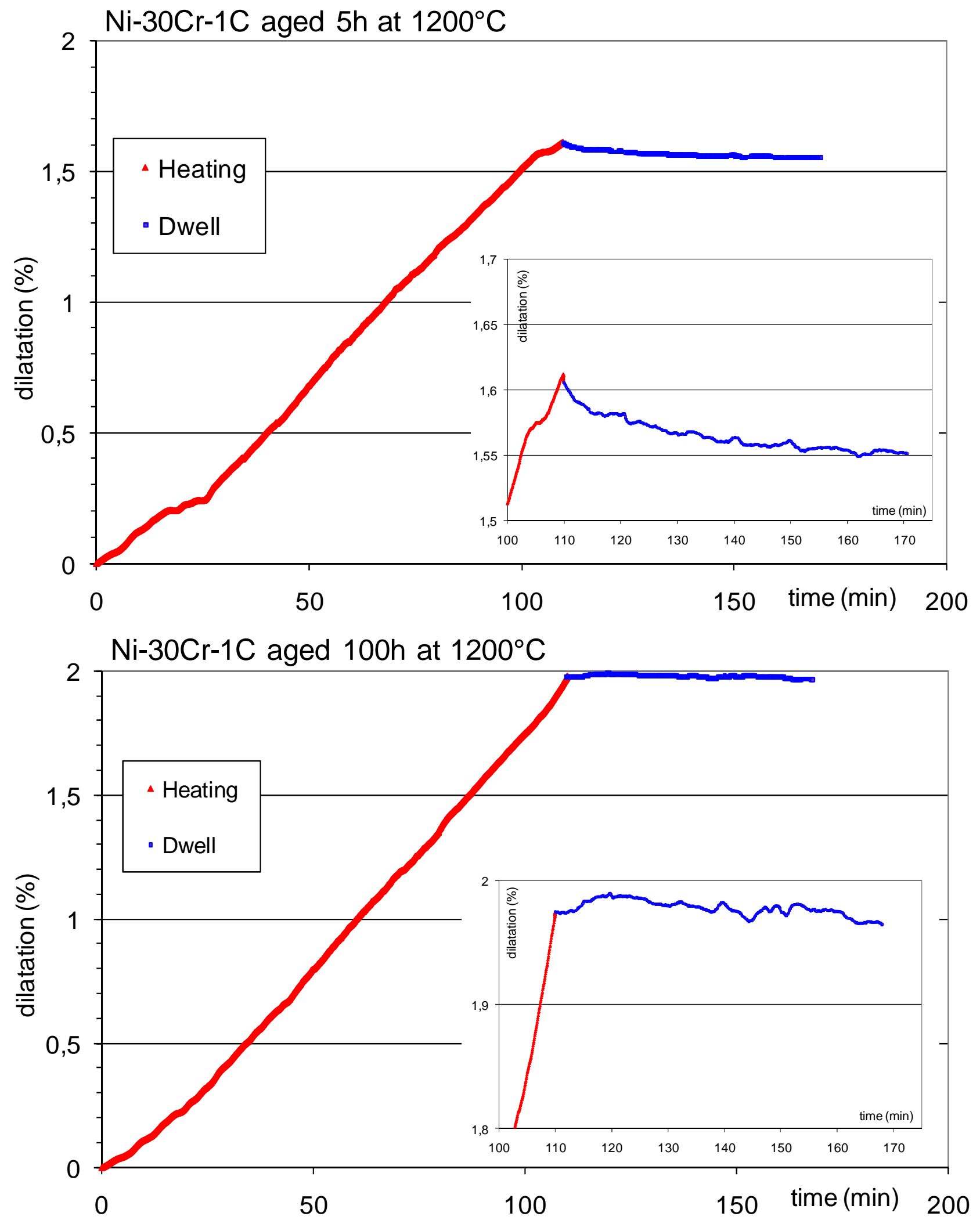

Fig. 9.

Dilatometry curves plotted as deformation versus time, with enlargement of the dwell part, in the case of the 5h-aged and 100h-aged Ni-based alloys 

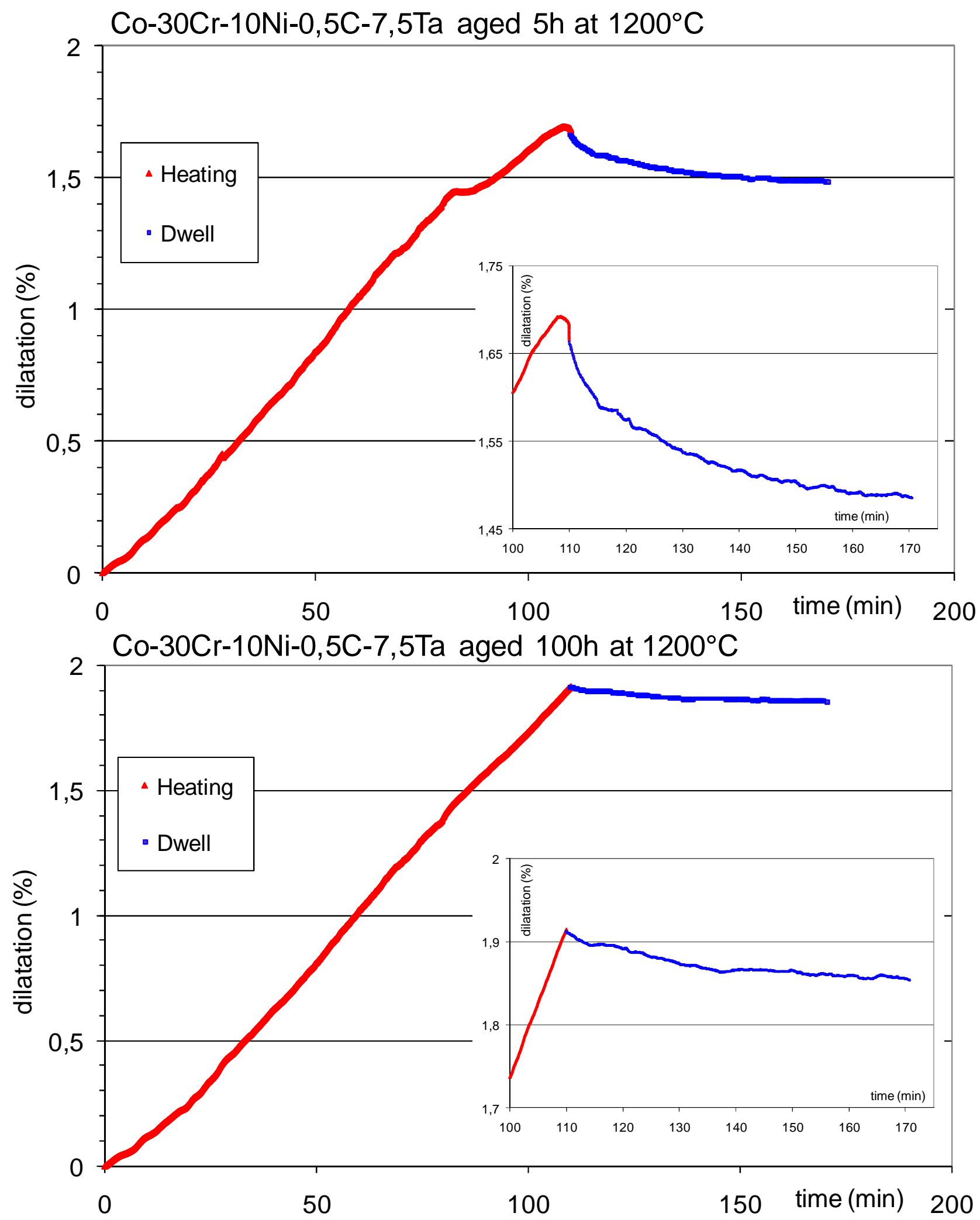

Fig. 10.

Dilatometry curves plotted as deformation versus time, with enlargement of the dwell part, in the case of the 5h-aged and 100h-aged Co-based alloys 


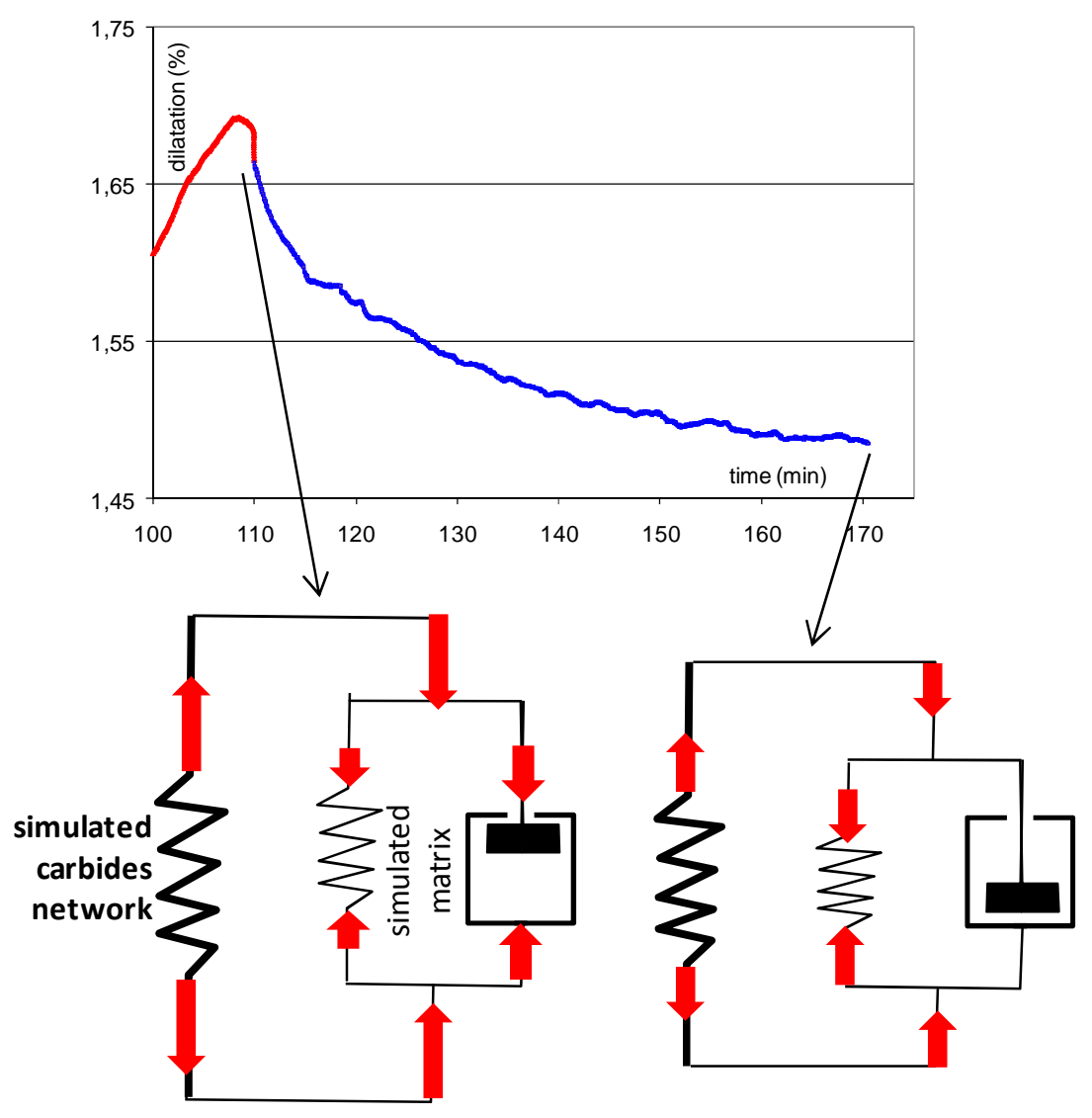

Fig. 11.

Mechanical scheme describing the proposed mechanism of isothermal contraction in the alloy arrived at $1200^{\circ} \mathrm{C}$ in the case of continuity still sufficient of the carbide network 